\title{
m-POGIL (modified-Process Oriented Guided Inquiry Learning) based Plas- tics Laboratory
}

\section{Dr. Spencer Seung-hyun Kim, Rochester Institute of Technology (CAST)}

Dr. Spencer Kim is an Associate Professor in Mechanical and Manufacturing Engineering Technology Department (MMET) at RIT, and serves as Associate Director of American Packaging Corporation Center for Packaging Innovation at RIT. He previously worked in the semiconductor industry. Dr. Kim, as a PI or Co-PI, received grants and sponsorship from NSF, SME, SPE, universities, and industries. In 2009 and 2013, he was nominated for the Eisenhart Award for Outstanding Teaching, RIT's premiere teaching award at RIT. Dr. Kim has directed numerous undergraduate research projects and several students won the first place in the undergraduate and graduate research competitions at the 2012 and 2013 GPEC (Global Plastics Environment Conference; Division of Society of Plastics Engineers). 


\section{m-POGIL (modified-Process Oriented Guided Inquiry Learning) based Plastics Laboratory}

\section{Introduction}

The higher education has strived towards reforming the undergraduate STEM education, so that traditional lecture-based instructions and laboratory exercises shift to more student-centered, active learning methods. As an innovative approach in student-centered, active learning methods, guided inquiry learning (GIL) has received wide attention and support from the STEM communities [1-3]. GIL is a pedagogical approach to active learning, driven by learner-centered and problem-based strategies emphasizing team-learning environment [1-4]. As the evidencebased research in education has grown on the effectiveness and potential of guided inquiry-based learning in the past few decades, an increasing number of colleges and institutions have adopted the GIL approach as a means to enhance and transform the teaching and learning experiences for instructors and students. The guided-inquiry-based instructional curricula resulted in significant learning gains in comparison to traditional instruction, and that most disadvantaged students benefited from inquiry-based instructional approaches [1-8].

Among the guided-inquiry-based learning methods, Process-Oriented-Inquiry Learning (POGIL) is a proven-pedagogical approach based upon the learning cycle model, which is composed of a learning cycle of exploration, concept invention, and application in learning [5-10]. In POGIL, the classroom or laboratory activities are driven by learner-centered and process-based strategies within team-learning environment. POGIL gives emphasis to a student-centered strategy in learning, so students work in small groups assigned with individual roles to ensure that all students are fully engaged in the learning process in various activities in classroom. Many studies reported the effectiveness of POGIL-based laboratories in chemistry, biosciences, engineering, and computer sciences education [5-11].

We designed and improved the materials and manufacturing curriculum by the POGIL approach, supported by a NSF grant (NSF AWRARD No.: DUE- 1044794). In addition, this NSF project could result in establishing an intensive undergraduate research activity for the manufacturing and mechanical engineering technology programs at our institute. As a result from the assessment and evaluation of the project, we were able to identify strengths and weaknesses to reform the traditional-transmission format for students' learning effectiveness in formative and summative purposes. The enhanced materials and manufacturing curriculum, based on the POGIL approach, indicated positive responses of the learning environment in various activities, in addition to differences of opinions from the students. In the NSF project, we conclude that the POGIL approach was a potentially useful and meaningful way to improve learning outcomes in the materials curriculum in engineering technology education. As a result from the project, we transformed a traditional practice-style to more student-centered, interactive, team-learning based method in materials education in engineering technology [6, 8, 12-16]. 
The plastics lab course needs to fulfill the instructional goals, students' specific characteristics, laboratory facilities, and educational resources for the ABET criteria in engineering technology. The current plastics laboratory course indicates deficiencies for undergraduate students to deal with complex material systems in characterization and testing for selection and design purposes. We develop the concepts involved in converting a traditional "verification" experiment (where the student verifies a principle taught in the classroom) to a "guided inquiry" experiment (where the student discovers the concept using the data and information collected.) and to reemphasize discovery-type experiments (i.e. research). The main purpose of this study was to develop and enhance plastics laboratory practices to increase engagements in an active-learning pedagogy through the modification of POGIL strategies. In addition, we attempted to convert experiments to the discovery format for low-level undergraduate students. We call this active learning method as "modified Process-Oriented-Guided-Inquiry-Learning ( $m$-POGIL)." The $m$-POGIL method differs from POGIL; the m-POGIL incorporates best practices in POGIL to produce the optimal learning experiences, but the lab-contents and experiments in the $m$-POGIL-based course are designed to focus on the ABET criteria for the engineering technology disciplines. Therefore, this paper describes the impact of m-POGIL-based laboratory activities on the context of active learning in a materials laboratory course; how students are engaged in learning; how students retain knowledge and develop skills in the characterization and testing principles in plastics. The assessment and evaluation of the m-POGIL approach for the study were conducted to improve student-learning environment in materials education.

\section{POGIL, $m$-POGIL and ABET}

Inquiry is an approach to learning whereby students discover various sources of information and ideas in order to use them to increase understanding of a problem, topic, or issue in the curriculum. Inquiry requires more from the students than simply answering questions or getting a right answer in learning [1-4]. In addition, inquiry requires an involvement with a community of students emphasizing social interaction in learning, even though it is often thought of as an individual pursuit. Process-Oriented Guided Inquiry Learning (POGIL) relies on inquiry-based, student-centered classrooms and laboratories that enhance learning skills while insuring content mastery. POGIL is designed to replace traditional lecture-only methods by encouraging students to discuss course materials, rather than listening to the instructor. POGIL based learning takes a different instructional approach than the traditional labs, though they cover the same core concepts in science, engineering and technology. Instead of seeking confirmation of concepts, POGIL-based classes allow students, with guidance, to observe phenomena, explore ideas, and find patterns allowing students to answer questions they have developed themselves [5-21]

The ABET emphasizes how things actually work, how they are made, and the realization that most mechanical components and assemblies become parts of complex systems, a consideration realized at the beginning of the design process [18]. In the ABET requirements and criteria, for mechanical engineering technology, the programs prepare graduates with knowledge, problem solving ability, and hands-on skills to enter careers in the design, installation, manufacturing, testing, technical sales, maintenance, and other endeavors typically associated with mechanical components and systems [18]. Therefore, the optimal methods of instruction are to bring some desired outcomes in knowledge and skills in materials and manufacturing technology for undergraduate students in the engineering technology programs. 


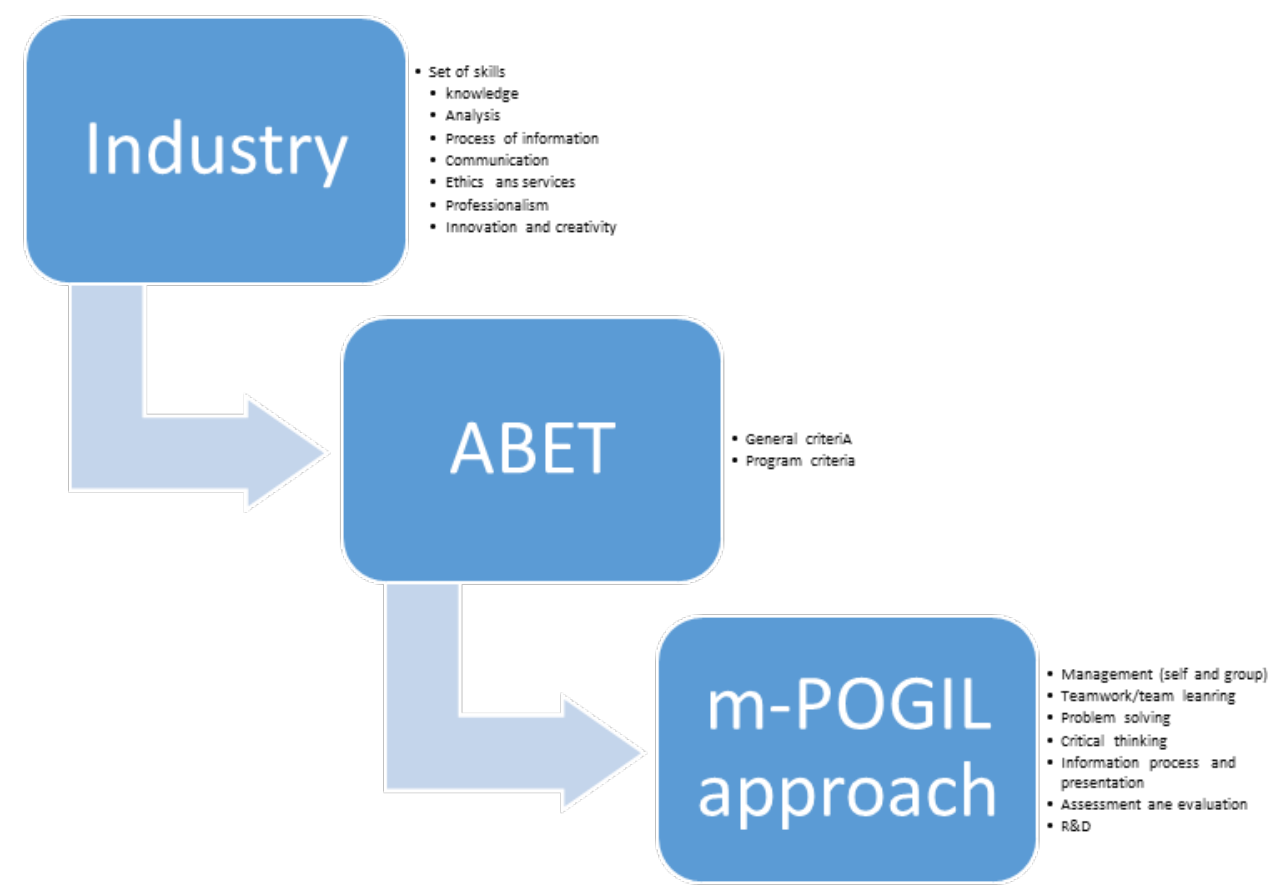

Figure 1: Transforming student learning-outcomes by m-POGIL

Figure 1 presents a schematic diagram to illustrate that $m$-POGIL approach is best suited to meet the ABET criteria, which are based on industry needs; such as problem solving, critical thinking, information process, teamwork, and management. In addition, the $m$-POGIL is to promote a direct experience with science fundamentals for students to explore the real applications, which led them to involve in the applied research works as undergraduate research experience (URE).

\section{Plastics Laboratory Activities by m-POGIL}

The $m$-POGIL adopts the pedagogic strategy of POGIL (Process-Oriented Guided Inquiry Learning) in which the instructional design is utilized by cognitive development and teamlearning environment. In order to fulfill the student's outcomes for the engineering technology programs according to the ABET criteria, we developed the contents and practices in $m$-POGIL based laboratory activities. Each lab experiment contains two separate activities; that is the prelab activity and lab experiment. The pre-lab activity surveys basic concepts and theories in polymers testing according to ASTM and ISO standards, whereas the lab experiment requires transforming acquired knowledge to produce a discovery or applications of the things in the lab experiment by guided inquiry. Table 1 summarizes a comparison of the main differences between three learning approaches. For example, instead of cooperating with each other within the groups in $m$-POGIL activity, individual students can gain initial understanding of basic concepts by completing a pre-lab activity at home. When students return to the lab, they can 
reinforce their understanding of the concept by communicating and practicing what they have learned at home.

Table 1: Main differences in three learning approaches

\begin{tabular}{|c|c|c|c|}
\hline & Traditional & POGIL & m-POGIL \\
\hline $\begin{array}{l}\text { Instructor's } \\
\text { involvement }\end{array}$ & $\begin{array}{l}\text { Full lecture is given and } \\
\text { instructor is involved } \\
\text { heavily. }\end{array}$ & $\begin{array}{l}\text { No lecture is given and } \\
\text { instructor works as a } \\
\text { facilitator. }\end{array}$ & $\begin{array}{l}\text { Pre-lab activity covers } \\
\text { fundamentals. (Work in } \\
\text { home.) Instructor } \\
\text { provides directions. }\end{array}$ \\
\hline Delivery & $\begin{array}{l}\text { - } \text { Guided by instructor. } \\
\text { - Work with lab manual. }\end{array}$ & $\begin{array}{l}\text { - Guided by POGIL } \\
\text { activity. } \\
\text { - Work within group }\end{array}$ & $\begin{array}{l}\text { - Guided by modified } \\
\text { POGIL activity } \\
\text { - Work within group } \\
\text { (or by individual) }\end{array}$ \\
\hline Experiment & $\begin{array}{l}\text { - } \quad \text { Verify concepts. } \\
\text { - } \quad \text { Detailed step-by-step }\end{array}$ & $\begin{array}{l}\text { - Verify or discover } \\
\text { concepts. } \\
\text { - Detailed step-by-step } \\
\text { by POGIL. }\end{array}$ & $\begin{array}{l}\text { - Discovery or/and } \\
\text { applications of } \\
\text { concepts. } \\
\text { - Less details in } \\
\text { guidance by m- } \\
\text { POGIL. } \\
\text { - Mini-research project } \\
\text { assigned } \\
\text { - Flexible scheduling }\end{array}$ \\
\hline Teamwork & - No need & - Need & $\begin{array}{l}\text { - Need, but individual } \\
\text { work allowed }\end{array}$ \\
\hline Use of the lab manual & $\begin{array}{l}\text { Directions in manual } \\
\text { make the lab work } \\
\text { possible. }\end{array}$ & - Use it as reference. & $\begin{array}{l}\text { - Not necessary } \\
\text { - Require information } \\
\text { and technical } \\
\text { resources }\end{array}$ \\
\hline $\begin{array}{l}\text { Evaluation and } \\
\text { assessment }\end{array}$ & - $\quad$ No required. & - No required & $\begin{array}{l}\text { - Required in } \\
\text { individual or/and } \\
\text { group work assigned. }\end{array}$ \\
\hline
\end{tabular}

The primary approach to developing and implementing the m-POGIL-based laboratory is to move away from the more "cookbook" structured lab, where students are typically told stepwise what to do in order to collect certain data and to conclude the experimental work. Then, students perform the lab experiment within the groups by desirable criteria for the $m$-POGIL lab-activity. The key desirable criteria for the $m$-POGIL lab activity are:

1. Making agreements, roles, and responsibilities, as a team-contract, for the teamwork.

2. Requiring generating experimental goal(s) and producing the outcomes.

3. Promoting active decision-making within the group.

4. Evaluating the individual and group performance.

5. Encouraging students to develop questions/or problems for further research.

6. Allowing student to work done independently.

\section{Characterization of nonmetals}

The laboratory course, "Characterization of nonmetals,” studies plastics testing principles of the American Society for Testing Materials (ASTM) and the ISO standards testing methods; various types of polymers, including green polymers, and composites are evaluated and characterized for 
materials selection and product design. This lab course is a core-required course that provides practices in the polymers testing to the lower level of students (i.e., 2nd year status) in manufacturing and mechanical engineering technology programs. Based on the ASTM and ISO standards, the emphasis is placed on analyzing experimental results and preparing professionalquality laboratory reports for plastics manufacturing technology. The lab practices emphasize the skills and knowledge needed in engineering tasks, such as communication, teamwork, decisionmaking, and problem solving, for manufacturing products. Table 2 shows typical laboratory topics covered in "Characterization of nonmetals."

Table 2: Plastics Laboratory Topics

\begin{tabular}{|ll|}
\hline \multicolumn{1}{|c|}{ Topics } \\
\hline 1) & Introduction to plastics testing \\
$\bullet$ & Lab introduction, safety and rules, care of equipment, and tour of the labs. \\
- & Teamwork for success and group assigned \\
2) & Survey of ASTM and ISO standards \\
3) & Materials specification and CES Edupack: use and selection of plastics for \\
& engineering design \\
4) & Internet resources and materials database for materials selection and design \\
5) & Polymerization (addition and condensation) \\
6) & Sample conditioning and preparation \\
7) & Plastics tensile testing: temperature, strain rate and environment Effects \\
8) & Plastics impact tests: Charpy- and Izod-impact testing \\
9) & Melt flow rate for plastics processability \\
10) & Plastics hardness testing: Rockwell hardness, Durometer hardness, Barcol \\
& hardness, and International hardness Testing \\
11) & Water absorption in thermoplastics \\
12) & Heat deflection test in engineering design \\
13) & 3D Printing (mini-research project): FDM and SLA \\
14) & Final group presentation \\
& \\
\hline
\end{tabular}


The course requires generating the learning outcomes as shown in Table 3. The course learning outcomes are correlated to the student outcomes given for engineering technology by the ABET criteria. These learning outcomes are used to create a student survey to measure the effectiveness and implication of the $m$-PGIL for the improvement of the lab course.

Table 3: List of learning outcomes (LOs) and student survey related to the ABET criteria of student outcomes

\begin{tabular}{|l|l|l|l|}
\hline No. & Learning Outcomes (LOs) & $\begin{array}{l}\text { ABET Criteria } \\
\text { for Student } \\
\text { Outcomes }\end{array}$ & $\begin{array}{l}\text { Student } \\
\text { Survey } \\
\text { Question } \\
\text { Number }\end{array}$ \\
\hline $\mathbf{1}$ & $\begin{array}{l}\text { I am able to search materials and materials } \\
\text { identification (non-metals), testing standards, and } \\
\text { testing method using library resources and internets. }\end{array}$ & a, c & Q1 \\
\hline $\mathbf{2}$ & $\begin{array}{l}\text { I am able to understand the materials specifications } \\
\text { and characterize the properties of non-metals for } \\
\text { design specifications. }\end{array}$ & a, c, d & Q2 \\
\hline $\mathbf{3}$ & $\begin{array}{l}\text { I am able to identify and select proper materials for } \\
\text { product design using technical information and } \\
\text { resources. }\end{array}$ & a, b, d & Q3 \\
\hline $\mathbf{4}$ & $\begin{array}{l}\text { I am able to analyze the lab experimental results and } \\
\text { to write technical laboratory report following ASTM } \\
\text { testing (or ISO method). }\end{array}$ & a, b, c, g, h & Q4 \\
\hline $\mathbf{5}$ & $\begin{array}{l}\text { I am able to organize ideas in a logical way to report } \\
\text { work done as well as to present a solution for } \\
\text { problem solving if needed. }\end{array}$ & b, c, d, f, g, h & Q5 \\
\hline $\mathbf{6}$ & $\begin{array}{l}\text { I am able to contribute knowledge and skills to } \\
\text { complete work in a timeline within the group } \\
\text { environment. }\end{array}$ & k, e, i, j, k & Q6 \\
\hline
\end{tabular}

\section{Instruction Design, Model, and Method}

The $m$-POGIL lab activity uses the principles of process-oriented, guided-inquiry learning (POGIL) in order to improve student learning with flexibility in the plastics laboratory course. The inquiry-based lab experiments emphasize studying principles and applications of the ASTM/ISO testing methods for selection and design purposes. In each experiment, students work with the pre-lab and the lab experiment through a learning process, which they are required to apply for testing principles, design of the lab experiment, performing the test, collecting data, model the data, discussing the meaning, and reporting the results. For a term project, which resembles the apprenticeship model of undergraduate research, the groups of students work with an experiment with faculty guidance to determine which testing method(s) is best suited for a research study. 
The $m$-POGIL lab-activity consists of prelab and lab-experiment in which each activity module contains the context of the POGIL approaches. In the lab activity, students (3-4 students per group) are assigned to work together within the groups at the laboratory. Each group begins an assigned lab work to recognize the need of a material (or materials) for a specific product design. The $m$-POGIL laboratory should engage students in realistic scientific inquiry and problem solving, in addition to teaching students' specific content and laboratory techniques. The $m$ POGIL activity-worksheet presents background, learning goals, scopes and uses of ASTM/ISO testing, materials information, technical resources and data, and applications of the testing principles. The problems in the activity-worksheet are to guide students toward the design of the lab experiment and formulation of their own conclusions. Students are encouraged to discuss and explain observed differences between the experimental and published values for the need recognition of the material tested and, thus, they can examine the validity of theoretical concepts, as well as uncertainties resulted from a laboratory process. Students were required to write a paper on the laboratory exercise, which is graded against a defined rubric that assesses the labwork on the activities, including standard test and theoretical approach, experimental process, data analysis, and discussion of the lab-results. The lab-instructor only serves as a facilitator, working with student groups if they need help during the lab. After students have completed the m-POGIL based lab activities, they design and perform the testing selected to investigate an advanced subject in materials and manufacturing; for example, we assign a project for students to study the mechanical properties of 3D printed PLA specimens. Figure 2 shows a flow diagram to implement the $m$-POGIL method based to on the active learning approaches.

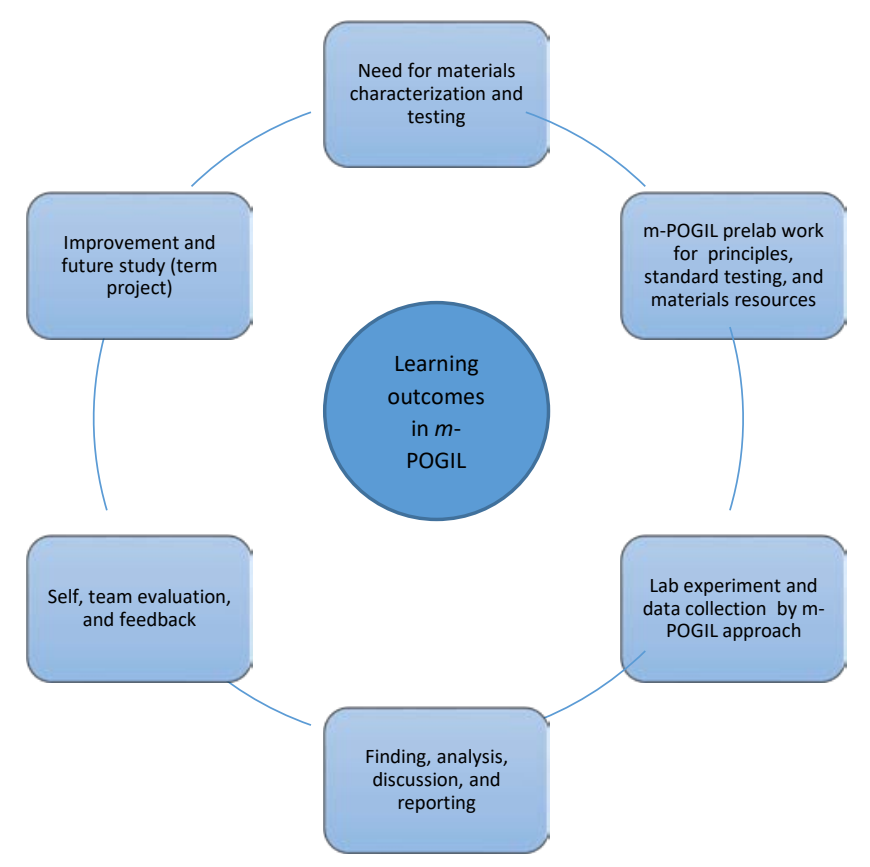

Figure 2: Instruction model by m-POGIL 


\section{Assessment and Evaluation}

The purpose of the assessment and evaluation was to investigate 1) how students felt about their $m$-POGIL learning experiences, and 2) how they performed the lab work to develop skills by the $m$-POGIL method. We analyzed three sections (i.e. Section 1, Section 2, and Section 3) of the $m$ POGIL lab in the fall of 2017-18; the total number of students in the m-POGIL lab sections was thirty-six $(n=36)$. After the laboratory experiments were completed, all participating students were asked to complete the surveys for the m-POGIL based lab-practices in order to monitor change in their learning outcomes (LOs) of the $m$-POGIL method in a time-interval; the surveys were given in Week 1, Week 6, Week 11, and Week 15 (last lab), respectively.

Table 1 shows that the questions of the survey indicate the learning outcomes (LOs) expected from students after the completion of the activity. These questions are designed to correspond to the ABET criteria for student outcomes in the curriculum. The results of the surveys were summarized and analyzed to understand the effectiveness and implication of the $m$-POGIL-based method in the materials laboratory education. In addition, these results of the surveys were implemented to evaluate and improve the instructional model and learning modules in the materials curriculum by the $m$-POGIL method.

\section{Findings}

Education benefits from assessment and evaluation to develop and improve the active learning environment for students [21]. The results of the assessment and evaluation help us become more confident in monitoring the students' success [6, 8, 12-16]. Their success can make them take some risk of continuing to try to study by a new way of practice. The survey results and responses were evaluated to demonstrate the extent of growth and the level of student's confidence for learning by the m-POGIL method, The extent of growth and the level of confidence in learning were measured in a survey scale of five; the numerical scale was from 5 (excellent) to 1 (very poor) at one unit interval. The scale was converted in percentage (\%) to measure the indication of the growth and confidence in learning. A threshold (i.e. 80\%) of numerical indicator was set as a measure in the appropriate level of student-confidence and, subsequently, of perceived student-learning gains in the $m$-POGIL based lab. Figure 3 shows the average-percentages of the growth and confidence in learning for Section 3 in a time-interval. 


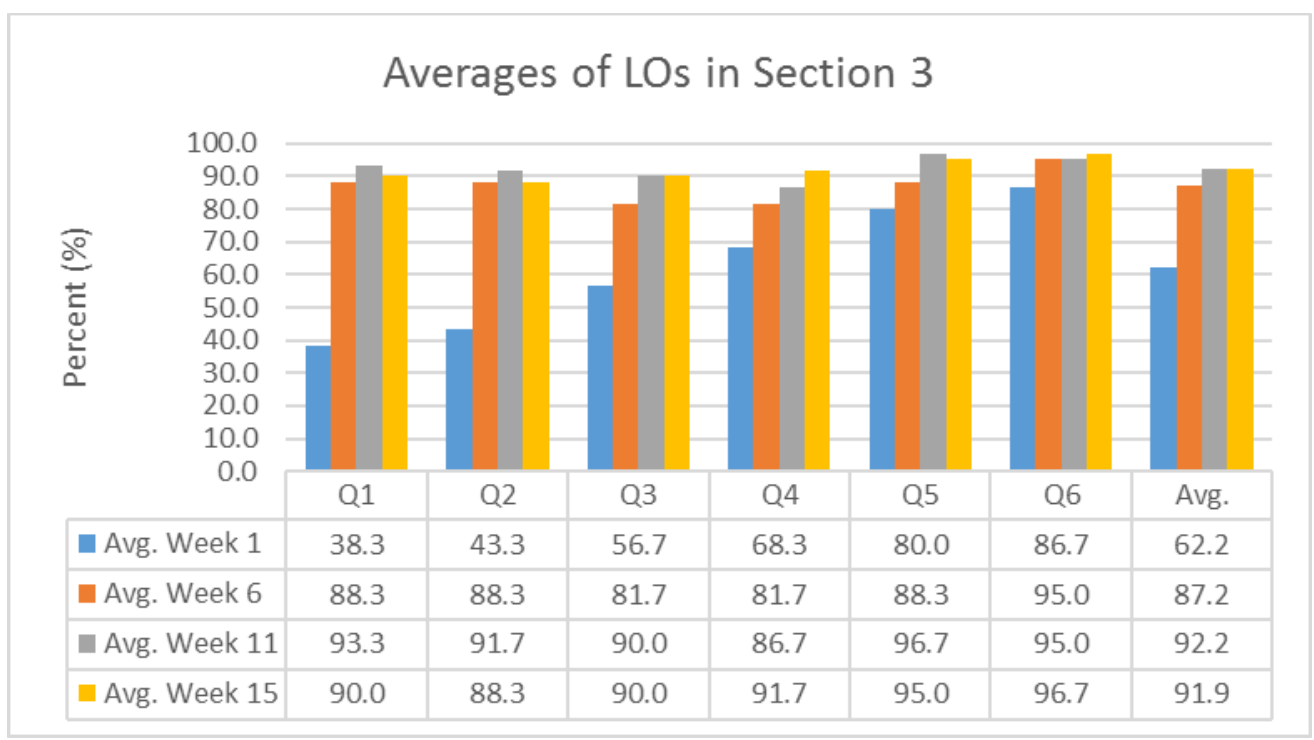

Figure 3: Averages of learning outcomes (LO) in Section 3

The survey questions of Q1, Q2, Q3, and Q4 were to assess and evaluate the effectiveness and implication of the $m$-POGIL method for students to study principles and applications in plastics characterization and testing for materials selection and design using the ASTM and ISO standards. These questions cover major skills required for students in engineering technology: such as finding information and resources, understanding specifications, generating an experimental goal, experimental design, following or developing testing procedure, data analysis and interpretation, and producing a quality report. The $m$-PGIL method resulted in the increased responses across the areas in active learning environment. As shown in Figure 3, the growth and confidence in learning increased with the $m$-POGIL based activities during the time, gradually and substantially. For example, $90 \%$ of students reported an increase in comfort with adapting the $m$-POGIL method from $38.3 \%$ to search materials and materials identification (non-metals) for the application and design purposes.

The ABET criteria require students to perform experiment, data analysis and interpretation, troubleshooting and solving, preparing quality report, and using data to design and planning future work [18]. The survey results show that strong/or positive agreements increase in the bar graphs in Figure 3. In Week 15, 95\% and 96.7\% of the students in Questions 4-5 reported increased confidence to perform the experiments and present the technical results, respectively. As we found, some students, who were accustomed to traditional learning format, were skeptical in active learning format [6, 12-15].

Question 6 represent team learning (or collaborative learning), which provides students one of the key elements to appreciate active learning environment in the $m$-POGIL laboratory. Students agreed upon the importance of preparedness and helpfulness of their group members during the activities as many POGIL curricula observed the similar responses in learning [5-9]. Even though learning experience can be improved by which students construct their knowledge and skills in teamwork, some students were not willing to contribute time and skills in the lab activities [6, 8, 12-15]. 


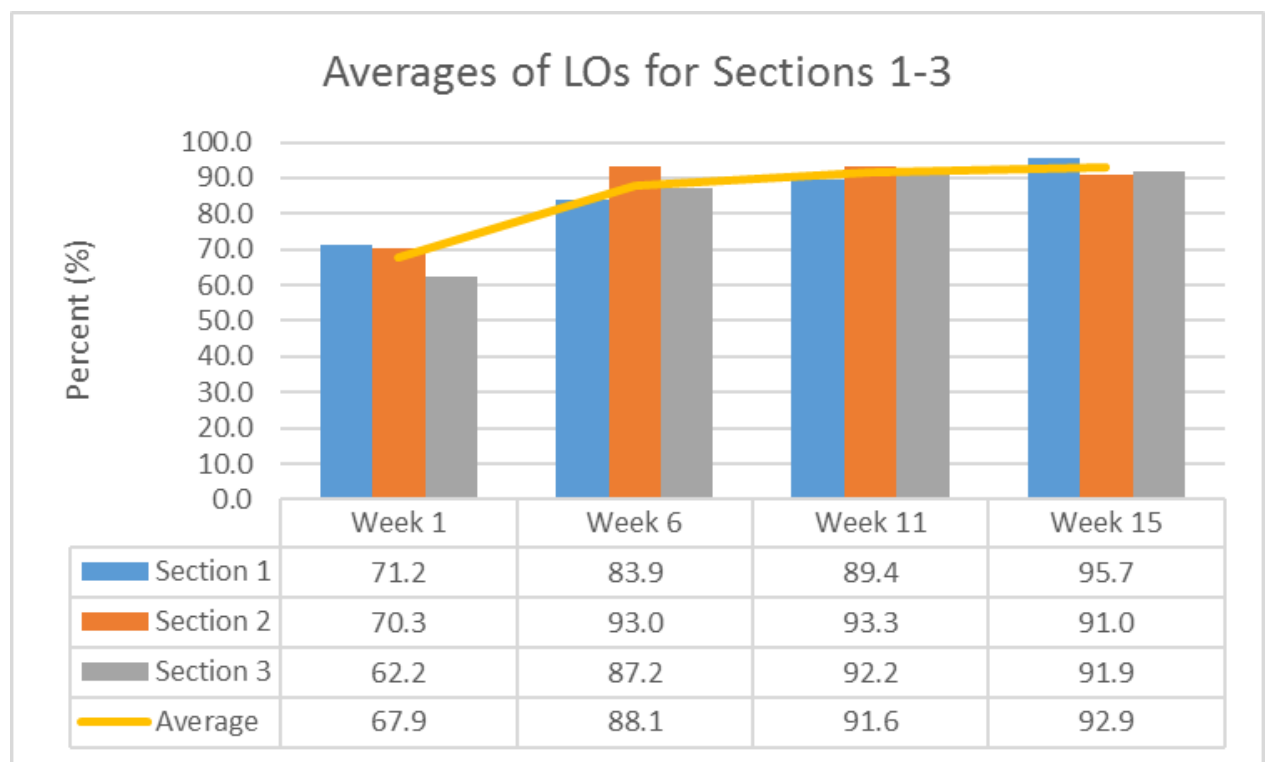

Figure 4: Average of learning outcomes for Section 1, Section 2, and Section 3

Figure 4 indicates the average percentages of the learning outcomes (LOs) to evaluate and measure the growth and confidence in learning for Sections 1, 2, and 3 during the periods. The $m$-POGIL laboratory practices require the students to work for meaningful learning activities by the guided inquiry and thus, students think about what they are doing in the activity assigned. These positive attitudes for active learning environment reflected the effectiveness of learning in various lab activities. The $m$-POGIL method expects students to use knowledge to solve any kind of problem. The average of learning outcomes increased from $67.0 \%$ to $92.9 \%$ during the periods. The study reported an increased level in all areas surveyed and provided strong confidence to use a proper skill level in practices with growth.

In the results of the assessment and evaluation, the study found that the process cycle proposed in Figure 2 provides the students with opportunities to practice the needed skills and receive feedback about their performance using the $m$-POGIL pedagogy. Students felt they already had a strong interest in study in advanced materials science and technology.

\section{Conclusion}

The study was to develop and enhance plastics laboratory practices to increase engagements in an active-learning pedagogy through the modification of POGIL strategies. The m-POGIL based lab attempted to convert the experiments to the discovery format for low-level undergraduate students in materials education emphasizing process skill and team learning. The m-POGIL based laboratory was able to enhance student's knowledge and to use proper techniques to solve problems in practices by the ASTM and ISO standards. The results from the completed surveys showed that a modified version of the POGIL method proved an effective way to provide an active learning environment for students to grow and increase the level of confidence in learning. The positive attitudes of students reflected the efficacy of the m-POGIL method to develop and improve various activities in materials education. The study reported an increased level in all areas surveyed and provided strong confidence to use a proper skill level in practices with 
growth. In conclusion, the m-POGIL method helps the students come to understand what it means to be in charge of their own learning process and thus, they can monitor their own success and make decisions that bring greater success.

\title{
Acknowledgement
}

\author{
This study is funded by PLIG (Provost Learning Innovation Grant) at RIT.
}

\section{Bibliography}

1. Michael Prince, "Does Active Learning work? A Review of the Research,” J of Eng. Edu., 1-9, July 2004.

2. Joel Michael, "Where's the evidence that active learning works?” Advances in Physiology Education, vol 30, pp. 159-167, December, 2006

3. A. Mohamed, "Effects of Active Learning Variants on Student Performance and Learning Perception," International J. for the Scholarship of Teaching and Learning, Vol. 2, No. 2, July 2008.

4. Jennifer L. Faust and Donald R. Paulson, “Active Learning in the College Classroom,” Journal on Excellence in College Teaching, 9 (2), 3-24, 1998.

5. Elliot P. Douglas and Chu C. Chiu, "Implementation of Process Oriented Guided Inquiry Learning (POGIL) in Engineering,” Advances in Engineering, ASEE, Winter 2013.

6. Spencer Kim and Betsy Dell, "Transforming Materials Education in Mechanical Engineering Technology,” 2012 Faculty Institute on Teaching and Learning, RIT, May 30-31, 2012.

7. Nibert Saltibus, "Analysis of the Traditional Method of Teaching and POGIL Employed in a OneSemesterEngineeringMaterialsTechnologyCourse,” Proceedings of ASEE 2017, Columbus, OH, June 25-28, 2017.

8. Spencer Kim, “Development of a Materials Laboratory Module in 3D Printing,” 2017 ASEE Annual Conference, Columbus, OH, June 25-28, 2017

9. Thomas Eberlein, Jack Kampmeier, Vicky Minderhout, Richard S. Moog|, Terry Platt, Pratibha VarmaNelson, and Harold B. White, "Pedagogies of Engagement in Science," Biochemistry and Molecular Biology Education, vol. 36 (4), pp. 262-273, 2008

10. POGIL, http://www.pogil.org/

11. Anthony Chase, Deblina Pakhira, and Marilyne Stains, "Implementing Process-Oriented, Guided-Inquiry Learning for the First Time: Adaptations and Short-Term Impacts on Students' Attitude and Performance,” J. Chem. Educ., 90, pp 409-416, 2013.

12. Spencer Kim, "Materials Education for Green Plastics Manufacturing Technology (GPMT)," 2012 ASEE Annual Conference, San Antonio, Texas, June 10-13, 2012.

13. Spencer Kim, "Transforming Curriculum for Workforce Development in Green Plastics Manufacturing Technology (GPMT),” 2013 CCLI/TUES Conference, Renaissance Hotel, Washington DC, Washington, District of Columbia, Jan. 21-22, 2013.

14. Spencer Kim, “Green Plastics Laboratory by Process Oriented Guided Inquiry Learning (POGIL),” 2014 ASEE Annual Conference, Indianapolis, Indiana, June 15 - 18, 2014.

15. Spencer Kim, "Materials Laboratory Designed by Process Oriented Guided Inquiry Learning (POGIL)," 2015 N. American Materials Education Symposium, Ohio State U., Columbus, OH, March 25-27, 2015.

16. Spencer Kim, "Transforming Curriculum for Workforce Development in Green Plastics Manufacturing Technology (GPMT) for STEM: Lesson Learned,” 123rd ASEE Annual Conference \& Exposition, New Orleans, LA, June 26 - 29, 2016.

17. David M. Hanson, Instructor's Guide to Process Oriented Guided Inquiry Learning, POGIL Project, May 2009. (http://new.pogil.org/downloads/pogil_ig.pdf)

18. ABET, http://www.abet.org/

19. Sally S. Hunnicutt, Alexander Grushow, and Robert Whitnell, "Guided-Inquiry Experiments for Physical Chemistry: The POGIL-PCL Model,” J. Chem. Educ. 92, pp 262-268, 2015. 
20. Sriram Sundararajan, "Developing inquiry-based laboratory exercises for a mechanical engineering curriculum,” 2012 Annual Conference for ASEE, San Antonio,” Texas, June 10-13, 2012.

21. David M. Hanson, Instructor's Guide to Process Oriented Guided Inquiry Learning, POGIL Project, May 2009. (http://new.pogil.org/downloads/pogil_ig.pdf) 